\title{
Supply chain risk, integration, risk resilience and firm performance in global supply chain: Evidence from Vietnam pharmaceutical industry
}

\author{
Xuan Hung Nguyen ${ }^{a}$, Tuan Anh Le ${ }^{a}$, Anh Tu Nguyen ${ }^{a}$, Thi Thu Hoai Pham ${ }^{\text {b* }}$ and Thi Ha Tran ${ }^{\mathrm{b}}$
}

${ }^{a}$ National Economics University, Vietnam

${ }^{b}$ University of Economics - Technology for Industries, Vietnam

\section{H R O N I C L E}

\section{Article history:}

Received September 18, 2020

Received in revised format May 8 , 2021

Accepted August 232021

Available online

August 232021

Keywords:

Supply chain risk

Supply chain Integration

Supply chain risk resilience

Global supply chain

Firm performance

Pharmaceutical

\section{A B S T R A C T}

The goal of the article is to examine the relationship between supply chain risk, Supply chain integration, Supply chain risk resilience and Firm performance in the global supply chain of the Vietnamese pharmaceutical industry. Data was collected for 3 months with 389 satisfied pharmaceutical enterprises for analysis on Smart PLS software. The results show that Supply chain risk has a statistically significant negative impact on supply chain integration. Moreover, Supply chain Integration has a statistically significant positive impact on Supply chain risk Resilience and firm performance. Finally, we find that Firm performance is a good foundation for business operations and supply chain risk resilience. Therefore, we make recommendations to Vietnamese pharmaceutical enterprises that: Supply chain Integration is extremely necessary to ensure performance and Supply chain risk resilience in the context of the current covid-19 pandemic.

(C) 2021 Growing Science Ltd. All rights reserved.

\section{Introduction}

Since ancient times, when it comes to the role of drugs, surely everyone will immediately think of the ability to prevent, cure, and enhance human health, medicine seems to have become an indispensable need for life. Associated with the development of the pharmaceutical industry, many new drugs have been prepared from which many diseases and dangerous diseases have also been overcome especially during the current Covid-19 pandemic. The demand for drugs and vaccines is huge. Research on the appropriate use of drugs and the production of new drugs has been a very attractive field for the application of new scientific achievements, aimed at helping people find a therapy against the development of drugs. The issue of ensuring that medicines protect human health is also one of the important standards in the system of world standards for assessing a country's standard of living. The guarantee of medicine, in many cases, is associated with saving human life or death. The problem of drug shortages can cause anxiety, negatively affect socio-political life, so the issue of drug assurance is still a relatively sensitive social issue that leaders of any country are interested.

Pharmaceutical is also a commodity, so it also has all the attributes of the commodity, the price of the drug will depend on the demand and supply in the market. The production and supply of pharmaceuticals is always strictly governed by the economic laws of goods such as the law of value, the law of competition, etc. In addition, pharmaceuticals also have their own characteristics. This is a type of commodity that especially may have a direct impact on human life and health, and it should be absolutely guaranteed in terms of quality, guided for safe, effective, and economical use. Therefore, pharmaceuticals require close management and support from the State and Ministries in research, business, import, export, and distribution, helping to preserve sociality and humanity. In addition, the pharmaceutical business is a highly exclusive and profitable

* Corresponding author

E-mail address: ptthoai@uneti.edu.vn (T.T.H. Pham)

(c) 2021 Growing Science Ltd. All rights reserved.

doi: $10.5267 /$ j.uscm.2021.8.010 
business. Therefore, new drugs circulating on the market often must be associated with the industrial monopoly of the pharmaceutical companies that have invested in research and production.

A pharmaceutical supply chain is a system of organizations, people, activities, information, and resources involved in moving pharmaceutical products from supplier or manufacturer to consumer (Consumer). Healthcare reform, expired technology and higher service requirements require pharmaceutical companies to adapt their business models and supply chains to adapt to changing market conditions. In the coming time, cutting costs, flexibly responding to market changes, and ensuring that complex legal frameworks are met will create many great challenges for companies operating in Vietnam. The pharmaceutical industry has its own set of challenges that have limited past efforts to improve supply chains. For example, quality standards can never be sacrificed to save costs, and regulatory constraints can prevent some initiatives that can improve economies of scale. Furthermore, to avoid the risk of running out of emergency drugs, most pharmaceutical companies will accept excess inventory. But in today's competitive business environment, companies must rethink the status quo and find innovative ways to stay one step ahead. To be successful, the pharmaceutical supply chain must be lean, low-cost and flexible - without compromising product and service quality. Therefore, in the supply chain of the pharmaceutical industry, there are many risks from inside as well as outside the enterprise. Pharmaceutical enterprises need to ensure product quality and bring business efficiency. Supply chain integration is a solution that has been discussed in many academic and practical studies. Supply chain integration reduces supply chain risks and improves business performance. Therefore, the objective of this paper is to assess the impact of supply chain risks in the pharmaceutical industry on the supply chain integration of these enterprises. At the same time, the study evaluates the impact of supply chain integration on the resistance to supply chain risks and operational efficiency of Vietnamese pharmaceutical enterprises. The layout of the article in addition to the introduction includes: Literature review; Research Methods; research results and conclusions.

\section{Literature review}

\subsection{Supply chain risk}

A supply chain is a system of organizations, people, activities, information, and resources involved in moving products or services from suppliers or manufacturers to consumers (Marucheck et al., 2011). According to Punniyamoorthy et al. (2013), Supply chain risk is "any risk in the flow of information, materials, and products from the original supplier to the delivery of the product to the final consumer". Or that risk may include "unexpected effects from major/small events or circumstances that adversely affect any part of the supply chain leading to irregularities or failures at the highest level." operational, tactical or strategic." Risks in the supply chain can also be divided according to the source of risk arising from the stakeholders in the supply chain (Punniyamoorthy et al., 2013).

Risks borne by the supplier

Supply chain risks caused by supplier stem from the following reasons:

- Poor supply quality.

- The inspection process is not clear.

- Sudden default.

- No know-how (engineering methods, special test conditions required, packaging tools, etc.)

- Change providers frequently.

- Complex critical materials.

Risk factors for businesses:

- Risk of raw materials.

- Risks on intellectual property.

- Risk of delivery time. 
Manufacturer's risk: Supply chain risk can come from the manufacturer's inability to meet product quality requirements (Sharma et al. 2016).

Supply chain risks due to the manufacturer stem from the following reasons:

- Insufficient production capacity.

- Not flexible in capacity.

- Unclear inspection and acceptance procedures.

- Inappropriate inventory management and maintenance strategy.

- Regular product recalls.

Risk factors:

- Risk of production interruption.

- Risk of losing core competencies due to sharing designs and documents with suppliers.

Demand risk

Supply chain risk due to unpredictability of customer demand. Causes of this risk may include:

- Unexpected or unstable customer demand.

- Error in demand forecast.

- Changes in customer preferences.

- Often slow delivery.

Risk factors:

- Acceptance risk.

- Reputational risk.

Logistics risks: Choosing the wrong shipping method can cause many risks in the supply chain

Supply chain risks on the logistics side stem from the following reasons:

- Choosing the wrong mode of transport.

- Incorrect packaging and marking.

- Poor traffic network design.

- Storage problems.

Risk factors:

- Risk of delivery time.

- Risk of cargo damage. 
Information risk

Risks in the supply chain due to information disruption stem from reasons such as:

- Choosing the wrong media, sharing information.

- Weak, undeveloped internal/external information infrastructure.

- The information system is not secure.

Risk factors:

- Lack of information internally and between partners in the supply chain leads businesses to not promptly handle arising situations. This affects the quality, production schedule, shipment... and hinders the current activities of the enterprise.

- Enterprise's information infrastructure has not yet met to connect the system with large customers, so they cannot access their orders.

- Information systems at enterprises are not really secure, so they are vulnerable to attacks.

Environmental risks

The risks in the supply chain due to environmental factors can stem from the following reasons:

- No skilled personnel.

- Unexpected events, force majeure such as: Strike, fire, riot, terrorism, war, natural disaster.

- Policy uncertainty.

- Macroeconomic uncertainty.

- Unstable society.

Risk factors:

- Operational risks.

- Product cost increases due to exchange rate fluctuations in payment transactions for importing raw materials

For example, the covid-19 pandemic has caused a huge impact and created a lot of risks in the supply chain of businesses in the economy in general and businesses in the pharmaceutical industry. Pharmaceutical enterprises are heavily affected by the supply and storage of vaccines against Covid-19.

\subsection{Supply chain integration}

To be successful, the pharmaceutical supply chain must be lean, low-cost and flexible - without compromising product and service quality. Unfortunately, the typical pharmaceutical supply chain is designed to focus on maximizing service levels in a stable business environment, not on responding quickly to changing needs (Phan et al., 2019). It is difficult to design and implement an overall optimal supply chain because of the different and conflicting goals of different parts and partners in the supply chain. However, in today's competitive market, most companies have no choice; they are forced to integrate their supply chains and engage in strategic collaboration. This pressure comes from both customers and partners in the supply chain. Therefore, businesses need to determine how much collaboration affects their success, what information can be shared during collaboration, as well as the appropriate level of integration and type of collaboration for each person. specific situations and projects (Tran et al., 2020). 


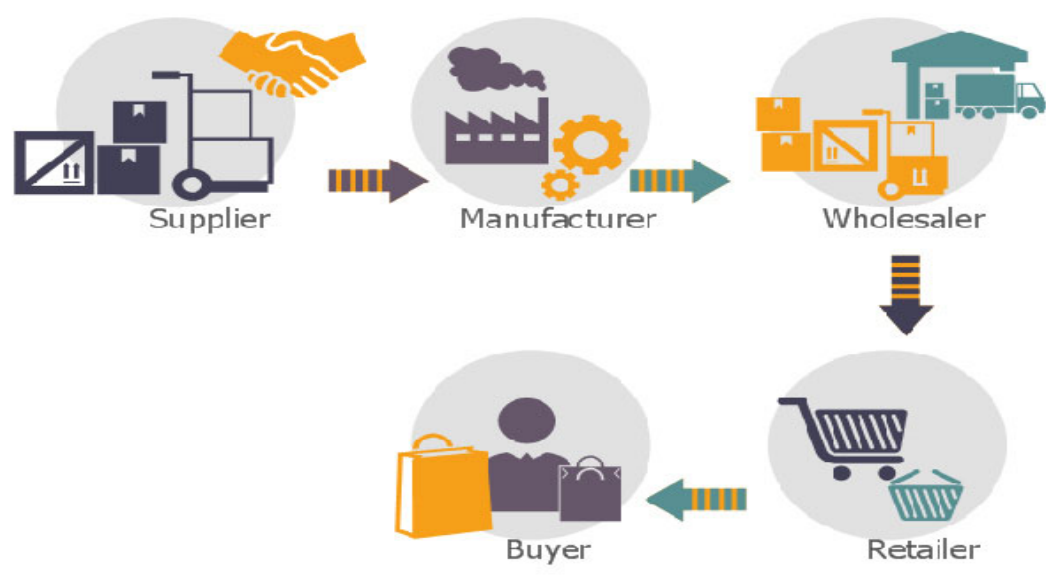

Fig. 1. Supply chain integration is an inevitable requirement for many businesses

\subsection{Supply chain risk resilience}

Supply chain disruptions have many origins: tariffs and trade disputes, natural disasters, pandemics, economic uncertainty, and cyberattacks (Linnenluecke, 2017). Each incident has its own issues, so it is difficult to plan an exact response to each incident. The goal is to build a supply chain that can last and recover from the inevitable disruptions from a wide range of threats. To do that, businesses must be able to react and adapt as quickly as possible to known and unknown risks. Supply chain disruptions are a fact of life for every company dealing in any kind of product. There will be no new normal, just new sources of disruption, from weather, government policies to industry conditions. Your organization's ability to predict disruptions, adapt to events, and build resilience comes from maintaining operational continuity. A wide range of events can prevent a business's supply chain from functioning properly, but not all events have the same impact. Inclement weather can shut down entire sites for short periods of time, but recovery can be quick. Other issues such as trade disputes and tariffs develop over the long term with a high degree of uncertainty. Your supply chain must be able to adapt to all kinds of threats (Nitya \& Singh, 2019). Supply chain resilience is a supply chain's ability to survive, adapt and thrive in the face of unexpected turbulent changes from pandemics, natural disasters, Covid-19 epidemic (Chopra \& Sodhi, 2014; Dubey et. al., 2019). Therefore, enterprises can manage risks arising from the business process due to risks from supply chain disruption such as risks from supply; Risk from customer demand will improve the competitive advantage of the firm (Gualandris \& Kalchschmidt, 2015). A supply chain built to be resilient allows a company to adapt to unpredictable forces while maintaining customer service. Conversely, supply chains that are too lean may not be flexible and redundant enough to survive normally. A resilient supply chain combines alternative sources, carriers, routes, and other characteristics so that it can be flexible in response to a situation (Shen $\& \mathrm{Li}$, (2017). Whether it's a pandemic like Covid-19, extreme weather events, trade and tariff disputes, economic volatility, or even an unexpected increase in customer demand, business, it is not possible to prepare for every situation. Large companies with established supply chain risk strategies cannot fully cope with the impact of the covid19 pandemic. Even in the worst times, an agile supply chain will flex and stretch but never break (Revilla \& Saenz, 2017). A resilient supply chain does not happen by itself. It is the result of a deliberate strategy that may require trade-offs compared to other approaches - which, in theory, is the result of supply chain integration planning.

\subsection{Firm performance}

Operational efficiency is understood in the most general sense as the economic, political, and social benefits that an individual or organization achieves during its operation (Pham \& Phan, 2020; Phan et al., 2020; Nguyen et al., 2020). For all enterprises, production and business units operating in the economy, with different management mechanisms, have different tasks and objectives. Even in each stage of business development, there are different goals, but it can be said that every enterprise operating in production and business with any type of ownership has the ultimate long-term overarching goal. Then, besides social efficiency, economic efficiency is the main criterion used to evaluate the performance of enterprises. To understand the concept of operational efficiency, it is necessary to consider the economic performance of a phenomenon. The economic efficiency of an economic phenomenon (or process) is an economic category that reflects the level of use of resources to achieve a specified goal, The results obtained, and all costs incurred to obtain that result, reflecting the quality of that economic activity. From the definition of economic efficiency of a phenomenon as above, we can understand that business performance of an enterprise is an economic category that reflects the level of use of resources to achieve a given goal. It represents the correlation between the results obtained and the costs incurred to get that result, the larger the difference between these two quantities, the higher the efficiency. 
Thus, if understood by purpose efficiency, operational efficiency is the difference between the results obtained and the cost of resources. Operational efficiency is enhanced in cases where results increase, costs decrease, and in cases where costs increase, but the rate of increase in results is faster than the rate of increase in costs spent to achieve that result.

\section{Research Method}

\subsection{Research background and sample}

During the period of impact of the Covid-19 pandemic, the demand for spending on health and medical products increased sharply. According to Business Monitor International (BMI), the scale of health spending in Vietnam will increase to 22.7 billion USD in 2021, with a compound growth rate (CAGR) of 12.5\% in the period of 2017. - 2021. According to a recent study by IMS Health, Vietnam is ranked in 17 countries in the group with the highest growth in the pharmaceutical industry (pharmerging markets) - a group of countries that are expected to become the mainstay of the pharmaceutical industry in the world. The development of the pharmaceutical industry is also facing great challenges. The growth of biology requires increasing costs of $R \& D(R \& D)$, production and distribution, companies that do not balance properly between revenue growth and cost containment will face serious problems. Of course, a good supply chain environment can create a strategic advantage if the business has the right technology support. Today's complex demand and supply networks require advanced, integrated logistics and supply chain planning solutions capable of taking advantage of a wide range of market opportunities. In addition, all market research figures show that the distribution channel of the pharmaceutical industry has not been able to promote its full strength as well as the advantages brought by the macro environment. Therefore, the application of technology solutions to the management and operation of the pharmaceutical supply chain will significantly save costs for businesses.

There are many pharmaceutical companies, but only 61 pharmaceutical companies are listed on the stock exchange. Among $18 / 61$ pharmaceutical enterprises that have announced their financial statements for the second quarter of 2021, equivalent to $66 \%$ of the industry's capitalization, the growth in net revenue and profit after tax reached $17.6 \%$ and 8 percent, respectively. Facing the COVID-19 pandemic, the business results of each pharmaceutical enterprise are somewhat different. According to the financial report for the second quarter of 2021, pharmaceutical enterprises in the lotus land of Dong Thap recorded more than 317.4 billion VND in net revenue, up nearly $10 \%$ over the same period last year. The company's profit after tax was VND 49.3 billion, a slight increase of $4.3 \%$. Accumulated in the first half of 2021, Imexpharm net profit after tax is 91.2 billion VND, up more than 3\% over the same period last year. In the second quarter, Central Pharmaceutical I - Pharbaco (PBC) also received joy when it achieved net revenue of more than 256.3 billion dong, profit after tax of nearly 12.3 billion $\mathrm{VND}$, an increase of more than $50 \%$ and $124 \%$ compared to the same period last year.

Accumulated in the first 6 months, this business has reached 476 billion VND in net revenue (up 26.7\% over the same period). Only in the first half of this year, Pharbaco's profit after tax was VND 26.6 billion (up 291\%), 2.7 times higher than the plan set out for the whole year. Pharbaco has a charter capital of 900 billion VND, ranking second in the industry, only after DHG Pharma (DHG). Summarizing the second quarter of 2021, OPC Pharmaceutical (OPC) achieved a revenue of 194.4 billion dong, a slight increase of $0.3 \%$ over the same period last year. However, OPC's profit after tax was reduced by more than $20 \%$, to 16.9 billion VND. OPC said the decrease in profit was due to increased costs incurred due to the complicated development of the COVID-19 epidemic. Accumulated in the first half of this year, OPC net profit after tax is 53.7 billion VND slightly increased by $0.2 \%$ compared to the same period last year. OPC Pharmaceutical, formerly Central Pharmaceutical Enterprise 26, was established at the end of 1977, based on merger from 8 private apothecaries in Ho Chi Minh City before. In 1994, this was the strongest export unit in Vietnam Pharmaceutical Corporation with a turnover of 1.4 million USD, contributing to bringing Golden Star Cao to 15 countries around the world. Kim Tien Thao kidney stone treatment, Dai Tonic Ginseng, Cao Ui model... are familiar products associated with the OPC name. In the same industry, CPC1 Central Pharmaceutical (DP1) is a first-class state-owned enterprise, formerly known as "Central State-owned Medicine and Pharmaceutical", born in 1956. In the second quarter of 2021, the company brought in 483 revenues of 7 billion dong, after-tax profit is 10.5 billion VND, up $6.3 \%$ and $9 \%$ respectively over the same period last year. However, adjusted gross profit margin decreased from 15\% to 13\%. Accumulated in the first half of this year, DP1 achieved revenue of 902.2 billion dong, down $8.5 \%$ compared to the first half of last year. However, the business still reaped 20.9 billion VND in after-tax profit, an increase of nearly 7\%. However, it is difficult for Vietnam's pharmaceutical industry to make a breakthrough because raw materials for production depend on $90 \%$ of imports, and China and India account for more than $80 \%$ of the supply. The arrival of the pandemic increases the challenge. To ensure the representativeness of the overall research is the pharmaceutical industry in Vietnam.

We selected the study sample by stratification and snowball methods as follows:

The research sample is enterprises in the pharmaceutical industry in Vietnam. We conduct online surveys and face-to-face interviews with Vietnamese pharmaceutical companies listed in the list of Vietnamese pharmaceutical companies published by the Vietnam Pharmaceutical Association. We randomly selected 500 enterprises, then stratified by region and stratified by size to ensure full size of enterprises and ensure representativeness by region. We sent survey questionnaires to all 500 businesses during 3 months from March 2020 to the end of May 2020. The results obtained 436 survey questionnaires, after reviewing and entering data. remaining 389 valid questionnaires for analysis. 


\subsection{Research model}

Fig. 2 present the structure of the proposed study.

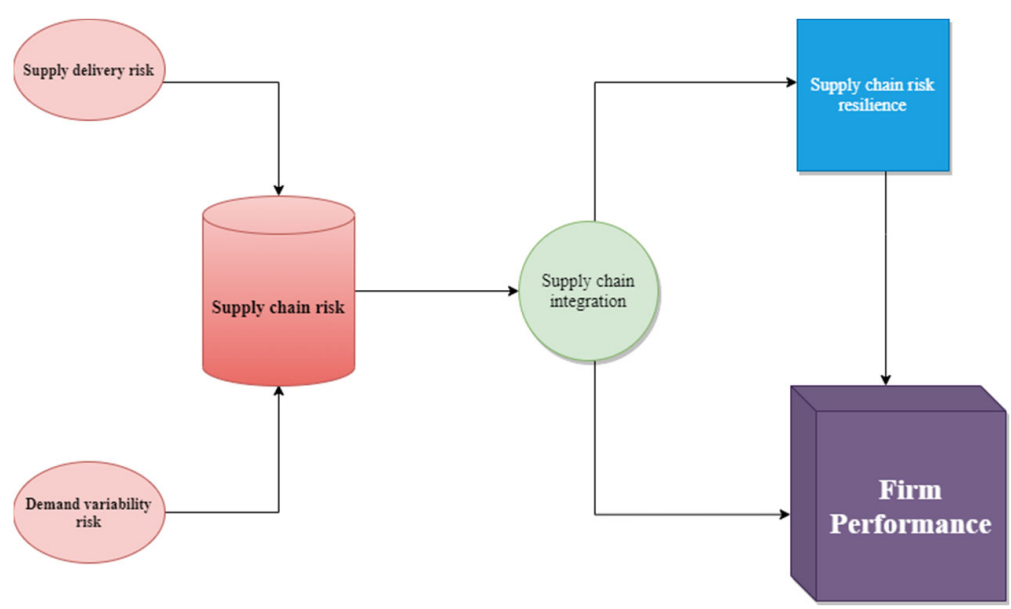

Fig.2. Research Model

Research model on the impact of supply chain risk on supply chain integration and supply chain resilience/risk tolerance on business performance of Vietnamese pharmaceutical enterprises. In which, the research variables in the research model are measured by the 5-point Likert scale with 1 being completely disagree to 5 being completely agree, the scales are developed from Nitya's research \& Singh (2019) and Zhao et al. (two thousand and thirteen); Yu et al. (2015) and Lu et al. (2021); Phan et al. (2020); Le et al. (2019); Phan et al. (2019), specifically as follows:

Supply of delivery risk (We have reversed all questions so that the impact indicators in the article are positive (contrary to theoretical expectations).

- Suppliers deliver on time.

- Suppliers regularly deliver full materials

- Short and efficient supplier search time in the supply chain

- Our company has short delivery times and avoids inventory and undersupply.

Risk of changing demand

- Our company has stable demand and orders

- The aggregate demand on our product distribution channels is very stable

- The demand for products of the factory is always forecasted in advance, determined stably

Vendor integration

- We maintain cooperative relationships with our suppliers.

- We help our suppliers improve their quality.

- We maintain close communication with our suppliers regarding quality considerations and design changes.

- Our suppliers are actively participating in our new product development.

- Our key suppliers provide input for our product development projects.

- We strive to establish long-term relationships with suppliers.

- We actively engage suppliers in our quality improvement efforts.

Customer integration

- We are in close contact with our customers on a regular basis. 
- Our customers give us feedback on our delivery quality and performance.

- Our customers are actively involved in our product design process.

- We work as a partner with our customers.

- We strive to meet the needs of our customers highly.

- We regularly survey the needs of our customers.

Internal integration

- Departments in the factory regularly communicate with each other.

- Our factory functions work well together.

- Our factory functions cooperate to resolve conflicts between them, as they arise.

- Our factory functions coordinate their activities.

- Plant functions interact with each other.

- We work as a team, with members from various fields (marketing, manufacturing, etc.) to introduce new products Risk resilience

- Our company has the resources to be ready in times of crisis, epidemic

- Our company can respond quickly when there is an interruption

- Our company can easily adapt to supply chain / business process disruptions

- Our company is able to maintain business continuity even after a supply chain / business process disruption event

- Our company is restored after a short interruption event

- Our company's crisis management ability reduces the impact of business loss

Gain time efficiency

- We usually meet the production schedule every day.

- Our daily schedule is reasonable and therefore can be completed on time.

- We usually complete our daily schedule as planned.

- We always stick to our schedule every day.

- We are always on schedule

Competitive performance

- Production unit price

- Conformity with product specifications

- Performance of on-time delivery

- Fast shipping

- Flexibility to change product mix

- Flexibility to change the volume

- Inventory turnover

- Cycle time (from raw material to delivery)

- Product capabilities and performance

- Right time to launch new products

- Product improvement 
- Customer service and support

Customer satisfaction

- Our customers are satisfied with the products and services we provide them.

- Our customers seem satisfied with our responsiveness to their problems.

- Our factory always meets the standards of customers.

- Our customers are very satisfied with the quality of our products for the past three years.

- Our organization meets or exceeds the requirements and expectations of our customers.

\subsection{Analytical techniques}

We use Excel 2020 software for initial data entry. Then, we used SPSS 23 software to test the reliability of the scale, analyze EFA - exploratory factor analysis. When the scale factors satisfy the reliability moderation, we use Smart PLS 3.3.6 software to test CFA - confirmatory factor analysis to test the overall reliability, discriminant validity, test the indicators of the measurement model and finally evaluate the structural model to test the research hypotheses. According to Hair et al. (2014), the number of studies using PLS-SEM published in recent years has increased rapidly. In the fields of organizational behavior, information system management, strategic management and in marketing research because PLS-SEM has many advantages over CB-SEM in the following situations: (1) Acceptance small sample size, data not normally distributed; (2) Can be used for complex research models with many intermediate, regulatory, latent and observed variables. Especially the structural model; (3) Capable of analyzing the structure of the result model (Reflective) and the cause model (Formative); (4) Suitable for predictive-oriented studies (Henseler et al., 2016). In addition, if non-normally distributed data are a big problem for CBSEM (i.e.: CB-SEM requires normally distributed data, this is said to be very difficult since studies are often surveyed by non-probability convenience methods). However, PLS-SEM is "very powerful" when using non-normally distributed data (Hair et al., 2013).

According to Hair et al. (2013), when using PLS-SEM technique, it is necessary to verify through 2 steps: (1) Check the measurement model; and (2) Verify the structural model. As follows:

(1) Evaluation of the measurement model:

- Reliability of indicator variables (or called observed variables)

In the outcome model (Reflective model), the indicator variables are explained by the latent variable, the load factor of the indicator variables $>=0.7$ (or 0.40 is acceptable in exploratory studies (Hair et al., 2012).

- Intrinsically consistent reliability

Intrinsically consistent reliability is measured through Cronbach's alpha value (Henseler et al., 2015) with an acceptable value of 0.7 in the initial research periods and each latent variable must have at least 2 indicator variables.

- Convergence value

Convergence value evaluates the relationship between indicators measuring the same latent variable. The convergence value of the scale is evaluated through:

- For exploratory studies, the composite confidence coefficient (CR) is in the range of $0.6-0.7$, but ideally should be $\geq 0.7$;

- The external load coefficient of the observed variables must be $\geq 0.708$;

- Average variance extracted AVE (Average variance extracted, reflecting the overall variability of observed variables calculated by latent variables) must be $\geq 0.5(0.7082=0.5)$ (Henseler et al., 2015); and Coefficient rho_A $>0.7$.

Discriminant validity measures discriminant validity to help ensure that there is no correlation between the factors used to measure the factors. Discriminant value is an important criterion in measurement model analysis. It measures the distinction between concepts in the research model (Henseler et al., 2015). There are two levels when considering discriminant validity, which are:

- The degree of distinction between components in the same concept (within construct, if it is a concept of level 2 or higher);

- The degree of cross construct between different concepts, or it refers to the critical measurement model (saturated model, the concepts in the research model are free to relate to each other).

The discriminant value is said to be eligible while the value of the criterion HTMT (heterotrait - monotrait) $<0.85$ (Henseler et al., 2015) or using the square root AVE of each measure is larger than the system. Latent variable correlations between that 
factor and other factors. In addition, in evaluating the measurement model, it is necessary to evaluate the multicollinearity of the indicator variables (VIF value $<5$, no multicollinearity). Henseler et al. (2015) said that, to be able to conclude that the model fits the market data (goodness of model fit), the following coefficients need to be satisfied:

- $\quad$ Coefficient SRMR (standardized root mean square residual) $<0.082$ (if the exploratory research type can accept $<0.12$ );

- $\quad$ Coefficient d_ULS $<95 \%$;

- $\quad$ Coefficient d_G1<95\%;

- Coefficient d_G2 $<95 \%$.

(2) Evaluation of structural model

The second step in PLS-SEM analysis is to evaluate the structural model through Bootstrapping method with sample size of 5000 (return-sampling). According to Hair et al. (2012b) proposed indicators in the evaluation of structural models include:

1) The coefficient of determining the variation of the model $\left(R^{2}\right)$,

2) Degree (intensity) of influence $\left(f^{2}\right)$

3) The influence factor (B) includes t values and confidence intervals,

- The coefficient of determination of the model's variation (Coefficient of determination, $\mathrm{R}^{2}$ )

The $\mathrm{R}^{2}$ value is defined as the percentage of variation in endogenous variables that is explained by exogenous variables (Hair et al. 2014). The $\mathrm{R}^{2}$ value ranges from 0 to 1 . The closer $\mathrm{R}^{2}$ is to 1 , the better the model fits the dataset. The closer $\mathrm{R}^{2}$ is to 0 , the less suitable the model is. Therefore, $\mathrm{R}^{2}$ results are important indicators of the relationship between latent variables in the model and are the main criteria for evaluating structural models (Hair et al., 2014).

Henseler et al. (2015) show that the acceptable level of ${ }^{2}$ depends on the research context. However, the rating is still given for reference respectively: strong (0.67), moderate $(0.33)$ and weak $(0.19)$.

- Degree of influence (Effect size, $\mathrm{f}^{2}$ )

Also according to Henseler et al. (2015) to consider the impact of exogenous variables on endogenous variables, it is necessary to evaluate the influence coefficient $\mathrm{f} 2$. When $\mathrm{f} 2$ is at 0.02 levels; 0.15 and 0.35 , it can be concluded that the impact level is weak, fair and strong, respectively.

- Path coefficient estimates

The coefficient of influence (ß) provides information about the strength of the relationship between exogenous and endogenous variables. The value of $\beta$ also indicates the directional relationship (positive or negative) of the concept in the research model (Henseler et al., 2015), corresponding to the tested hypothesis. To determine the significance of the relationship, the Bootstrapping approach is proposed (Hair et al. 2014). The Bootstrapping method uses resampled sampling $(n=5000)$ to estimate the accuracy of the PLS estimates by replacing sampling from the original data set (Hair et al. 2014). The results of the $t$-statistic can be used to determine the significance level ( $p$-value). Accordingly, the statistical value $t=$ 1.6497 corresponds to the $90 \%$ confidence level; $t=1.9676$ corresponds to $95 \%$ confidence and $t=2.5916$ corresponds to $99 \%$ confidence.

\section{Result}

The results of testing the reliability of the scale on SPSS 23 software show that all scales satisfy the conditions. At the same time, the results of the EFA exploratory factor test also show the factors that satisfy the analytical conditions. Therefore, we evaluate the overall reliability and discriminant validity on Smart PLS 3.3.6 software with the following results:

Table 1

Construct Reliability and Validity

\begin{tabular}{|c|c|c|c|c|}
\hline & Cronbach's Alpha & rho_A & Composite Reliability & Average Variance Extracted (AVE) \\
\hline Competitive performance & 0.887 & 0.887 & 0.887 & 0.662 \\
\hline Customer integration & 0.838 & 0.843 & 0.839 & 0.635 \\
\hline Customer satisfaction & 0.872 & 0.872 & 0.872 & 0.695 \\
\hline Demand variability risk & 0.867 & 0.874 & 0.868 & 0.571 \\
\hline Firm Performance & 0.953 & 0.953 & 0.953 & 0.669 \\
\hline Internal integration & 0.920 & 0.921 & 0.920 & 0.697 \\
\hline Schedule attainment & 0.872 & 0.873 & 0.872 & 0.694 \\
\hline Supplier integration & 0.945 & 0.945 & 0.945 & 0.774 \\
\hline Supply chain risk & 0.947 & 0.949 & 0.948 & 0.647 \\
\hline Supply chain risk resilience & 0.932 & 0.933 & 0.932 & 0.776 \\
\hline Supply delivery risk & 0.916 & 0.917 & 0.916 & 0.687 \\
\hline
\end{tabular}


From Table 1, it is shown that all factors have Cronbach Alpha coefficients and AVE coefficients that satisfy the combined reliability conditions that Hair et al. (2014, 2017), Chin (2010) and Hesenler et al. (2009; 2015) released. Therefore, it is satisfied to perform the next test.

Table 2

Discriminant Validity (Fornell-Larcker Criterion)

\begin{tabular}{|c|c|c|c|c|c|c|c|c|c|c|c|}
\hline & 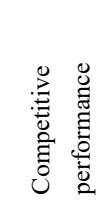 & 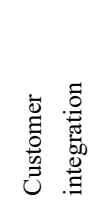 & 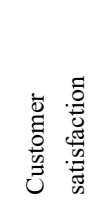 & 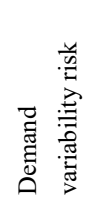 & 吾 & 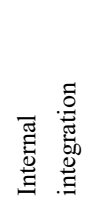 & 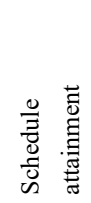 & 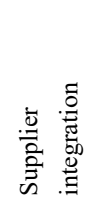 & 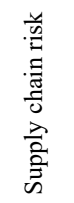 & 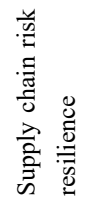 & 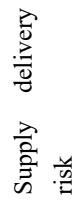 \\
\hline Competitive performance & 0.814 & & & & & & & & & & \\
\hline Customer integration & 0.177 & 0.797 & & & & & & & & & \\
\hline Customer satisfaction & 0.009 & 0.152 & 0.833 & & & & & & & & \\
\hline Demand variability risk & 0.338 & 0.358 & 0.334 & 0.755 & & & & & & & \\
\hline Firm Performance & 0.053 & 0.184 & 0.039 & 0.339 & 0.818 & & & & & & \\
\hline Internal integration & 0.454 & 0.223 & 0.496 & 0.546 & 0.464 & 0.835 & & & & & \\
\hline Schedule attainment & 0.270 & 0.221 & 0.337 & 0.334 & 0.023 & 0.431 & 0.833 & & & & \\
\hline Supplier integration & 0.146 & 0.359 & 0.155 & 0.408 & 0.157 & 0.236 & 0.169 & 0.880 & & & \\
\hline Supply chain risk & 0.311 & 0.338 & 0.311 & 0.081 & 0.315 & 0.536 & 0.314 & 0.380 & 0.804 & & \\
\hline Supply chain risk resilience & 0.561 & 0.236 & 0.508 & 0.394 & 0.561 & 0.380 & 0.596 & 0.273 & 0.364 & 0.881 & \\
\hline Supply delivery risk & 0.295 & 0.330 & 0.299 & 0.056 & 0.302 & 0.542 & 0.305 & 0.365 & 0.059 & 0.348 & 0.829 \\
\hline
\end{tabular}

The research variables all satisfy the discriminant validity because the values outside the diagonal are smaller than the values on the diagonal according to Hair et al. (2014; 2017) and Henseler et al. (2009;2015).

Table 3

The results of R-square

\begin{tabular}{|c|c|c|c|c|c|}
\hline & R Square & R Square Adjusted & & R Square & R Square Adjusted \\
\hline Competitive performance & 0.211 & 0.210 & Schedule attainment & 0.266 & 0.265 \\
\hline Customer integration & 0.287 & 0.285 & Supplier integration & 0.258 & 0.260 \\
\hline Customer satisfaction & 0.278 & 0.286 & Supply chain risk & 0.327 & 0.326 \\
\hline Firm Performance & 0.390 & 0.384 & Supply chain risk & 0.282 & 0.280 \\
\hline Internal integration & 0.289 & 0.292 & & & \\
\hline
\end{tabular}

Table 4

The results of F-square

\begin{tabular}{|c|c|c|c|c|c|c|c|c|c|c|c|}
\hline & 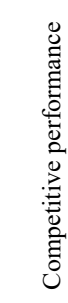 & 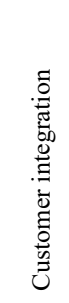 & 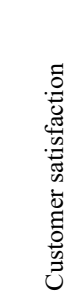 & 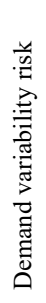 & 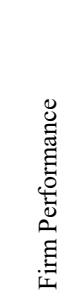 & 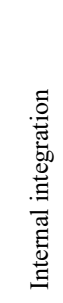 & 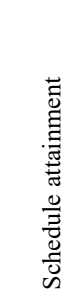 & 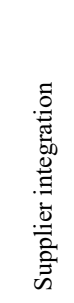 & 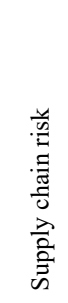 & 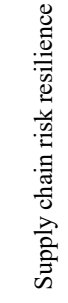 & 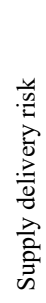 \\
\hline \multicolumn{12}{|l|}{ Competitive performance } \\
\hline Customer integration & & & & & 0.268 & & & & & 0.235 & \\
\hline \multicolumn{12}{|l|}{ Customer satisfaction } \\
\hline Demand variability risk & & & & & & & & & 0.222 & & \\
\hline Firm Performance & 0.224 & & 0.235 & & & & 0.232 & & & & \\
\hline Internal integration & & & & & 0.239 & & & & & 0.256 & \\
\hline \multicolumn{12}{|l|}{ Schedule attainment } \\
\hline Supplier integration & & & & & 0.244 & & & & & 0.278 & \\
\hline Supply chain risk & & 0.274 & & & & 0.403 & & 0.168 & & & \\
\hline Supply chain risk resilience & & & & & 0.256 & & & & & & \\
\hline Supply delivery risk & & & & & & & & & 0.548 & & \\
\hline
\end{tabular}


Table 5

The summary of Model fit

\begin{tabular}{lcc} 
& & Saturated Model \\
SRMR & 0.056 & 0.058 \\
d_ULS & 0.837 & 0.856 \\
d_G & 0.845 & 0.888 \\
Chi-Square & 902.245 & 911.298 \\
NFI & 0.887 & 0.890 \\
\hline
\end{tabular}

Thus, the tests to evaluate the measurement model all satisfy the research conditions. The research data is consistent with the research model and the scales of the latent research variables satisfy the testing conditions. Next, we test the research hypotheses with the following test results:

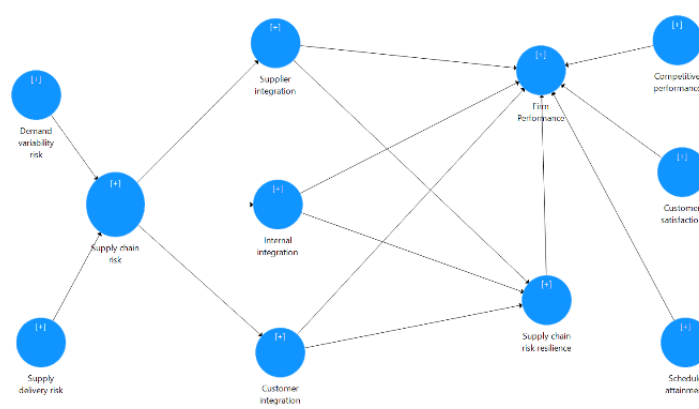

Fig. 3. The summary of the proposed model

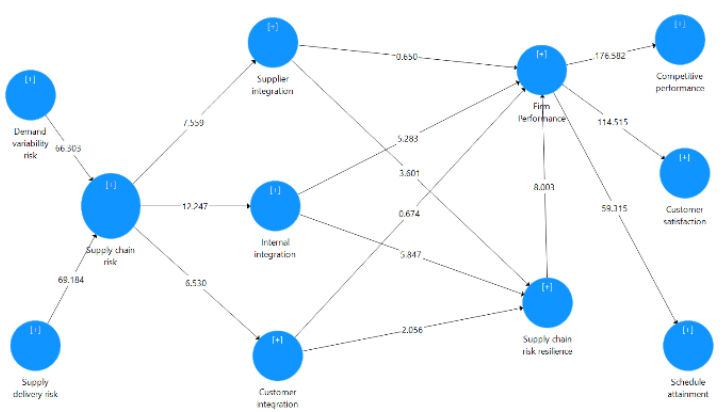

Fig. 4. The summary of t-value

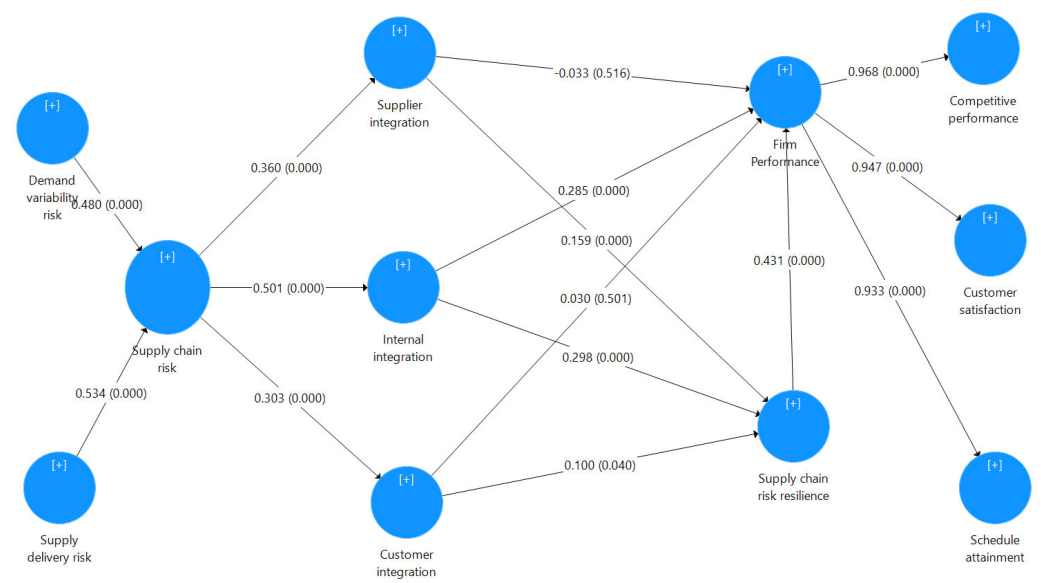

Fig. 5. The summary of the results of hypotheses testing

From the results in Figs. 3-5, most of the proposed hypotheses are specifically accepted as follows:

Risk in supply and risk in demand are two structural variables of Supply chain risk with coefficients of production 0.480 and 0.534 respectively, both at $1 \%$ significance level. This means that supply chain risk is made up of two aspects, demand variability risk and supply delivery risk. Next, since the questions have been reversed coded by us, supply chain risks have a positive impact on supply chain integration with a positive impact factor. It essentially means that supply chain risk negatively impacts supply chain integration. In other words, Supply chain risk has a negative impact with a fairly strong impact on supplier integration with an impact factor of 0.360 at $1 \%$ significance level $\left(\mathrm{P}_{-}\right.$value $\left.=0.000\right)$; Supply chain risk has a very strong negative impact on Internal Integration with an impact factor of 0.501 at $1 \%$ significance level $\left(\mathrm{P}_{-}\right.$value $\left.=0.000\right)$; Finally, Supply chain risk negatively affects Customer integration with a strong coefficient of 0.303 at $1 \%$ significance level $\left(P_{-}\right.$value $\left.=0.000\right)$. We next evaluate the role of Supply chain Integration in performance and supply chain risk resilience. Supplier Integration has a positive impact on Supply chain risk resilience with an average impact coefficient of 0.159 at $1 \%$ significance level $(\mathrm{P}-$ value $=0.000)$. However, there is not enough evidence to confirm that Supplier Integration has a statistically significant impact on Firm performance. Internal Integration has a statistically significant positive effect on both Firm performance and Supply chain risk resilience with the respective impact coefficients of 0.285 and 0.298 at the same $1 \%$ significance level $(\mathrm{P}-\mathrm{value}=0.000)$. Finally, Customer Integration has a positive impact on Supply chain risk resilience at the weak level of 0.100 and at the $5 \%$ significance level $(\mathrm{P}-$ value $=0.040)$. However, Customer Integration does not have a statistically significant impact on Firm performance. Bootstrapping results also show that Firm performance is reflected in 
three aspects: Competitive performance; Customer satisfaction and Schedule attainment. This means three aspects of Competitive performance; Customer satisfaction and Schedule attainment are reflective constructs. Table 6 summarizes the results of the hypothesis testing as follows:

Table 6

Path Coefficients (Mean, STDEV, T-Values, P-Values)

\begin{tabular}{|c|c|c|c|c|c|}
\hline & $\begin{array}{c}\text { Original } \\
\text { Sample }(\mathrm{O})\end{array}$ & $\begin{array}{c}\text { Sample } \\
\text { Mean (M) }\end{array}$ & $\begin{array}{c}\text { Standard Deviation } \\
\text { (STDEV) }\end{array}$ & $\begin{array}{c}\text { T Statistics } \\
(|\mathrm{O} / \mathrm{STDEV}|)\end{array}$ & $\begin{array}{c}\mathrm{P} \\
\text { Values }\end{array}$ \\
\hline Customer integration $\rightarrow$ Firm Performance & 0.030 & 0.031 & 0.044 & 0.674 & 0.501 \\
\hline Customer integration $\rightarrow$ Supply chain risk resilience & 0.100 & 0.101 & 0.049 & 2.056 & 0.040 \\
\hline Demand variability risk $\rightarrow$ Supply chain risk & 0.480 & 0.480 & 0.007 & 66.303 & 0.000 \\
\hline Firm Performance $\rightarrow$ Competitive performance & 0.968 & 0.969 & 0.005 & 176.582 & 0.000 \\
\hline Firm Performance $\rightarrow$ Customer satisfaction & 0.947 & 0.947 & 0.008 & 114.515 & 0.000 \\
\hline Firm Performance $\rightarrow$ Schedule attainment & 0.933 & 0.933 & 0.016 & 59.315 & 0.000 \\
\hline Internal integration $\rightarrow$ Firm Performance & 0.285 & 0.284 & 0.054 & 5.283 & 0.000 \\
\hline Internal integration $\rightarrow$ Supply chain risk resilience & 0.298 & 0.299 & 0.051 & 5.847 & 0.000 \\
\hline Supplier integration $\rightarrow$ Firm Performance & -0.033 & -0.033 & 0.052 & 0.650 & 0.516 \\
\hline Supplier integration $\rightarrow$ Supply chain risk resilience & 0.159 & 0.158 & 0.044 & 3.601 & 0.000 \\
\hline Supply chain risk $\rightarrow$ Customer integration & 0.303 & 0.304 & 0.046 & 6.530 & 0.000 \\
\hline Supply chain risk $\rightarrow$ Internal integration & 0.501 & 0.502 & 0.041 & 12.247 & 0.000 \\
\hline Supply chain risk $\rightarrow$ Supplier integration & 0.360 & 0.361 & 0.048 & 7.559 & 0.000 \\
\hline Supply chain risk resilience $\rightarrow$ Firm Performance & 0.431 & 0.431 & 0.054 & 8.003 & 0.000 \\
\hline Supply delivery risk $\rightarrow$ Supply chain risk & 0.534 & 0.534 & 0.008 & 69.184 & 0.000 \\
\hline
\end{tabular}

To explain more specifically, we test the impact of Supply chain Integration on each aspect of performance with the test model and the results are as follows:

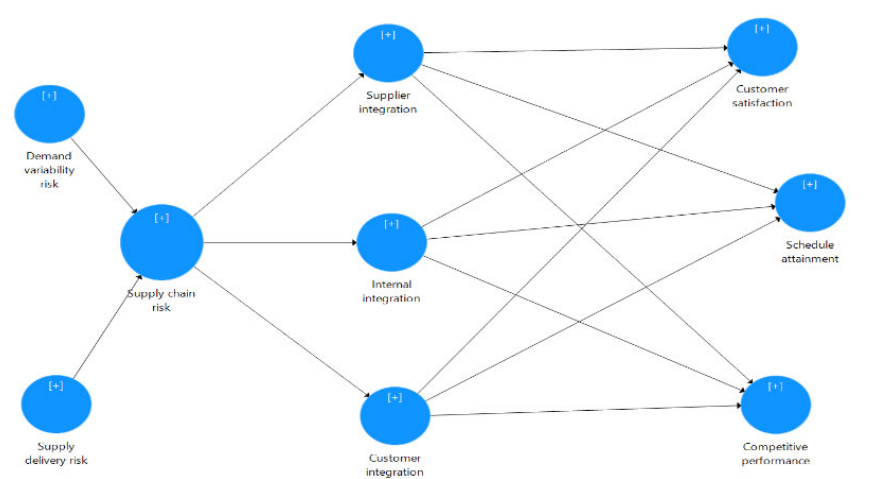

Fig. 6. Supply chain Integration's direct impact on every aspect of performance

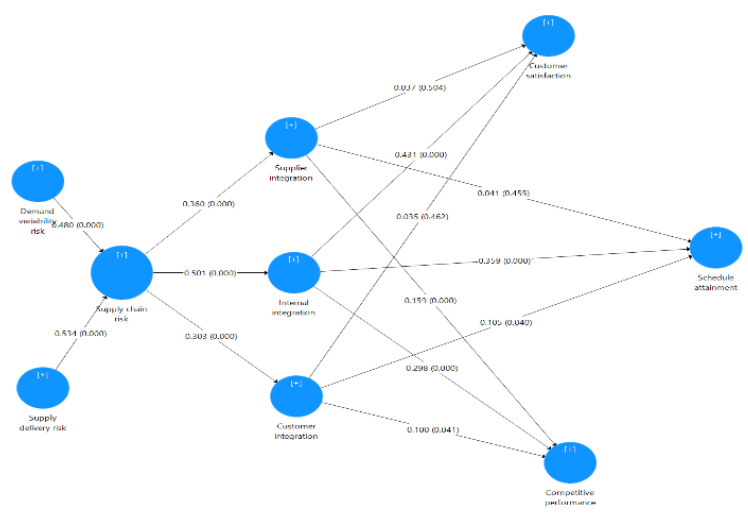

Fig. 7. More detailed results

The results in Fig. 7 show that, although in the overall SEM Supplier Integration model, there is no statistically significant impact on Firm performance. However, in a detailed model of each performance aspect, it shows that Supplier Integration has a statistically significant impact on Competitive performance with an impact factor of 0.159 at $1 \%$ significance level (P-value $=0.000)$ and still There was no statistically significant impact on the other two performance dimensions, Schedule attainment and Customer satisfaction. Therefore, in the Supplier Integration aggregate model, there is still no statistically significant impact on firm performance. Internal Integration still had a statistically significant impact on all three aspects of firm performance with coefficients of 0.431 , respectively; $0.359 ; 0.289$ with 3 aspects respectively Customer satisfaction; Schedule attainment and Competitive performance and both are at $1 \%$ significance level ( $\mathrm{P}$ - value $=0.0000)$. Customer Integration has a very weak statistically significant impact on two aspects of firm performance with coefficients of 0.105 and 0.100 , respectively, with two aspects, Schedule attainment and Competitive performance, respectively, and both at the 5\% significance level ( $\mathrm{P}$ - value $>0.000$ ), and Customer Integration had no statistically significant impact on Customer satisfaction. This explains in more detail why Customer Integration has no statistically significant impact on Firm performance. The above analysis results show that the role of Internal Integration is very important in pharmaceutical 
enterprises in Vietnam. Therefore, Vietnamese pharmaceutical enterprises need to have a supply chain integration strategy, although the focus and most importantly integration is from within the enterprise first. If internally united and strong, it will bring competitive advantages and sustainable development to businesses during the current pandemic.

The summary results of the research hypothesis are as follows:

Next, we examine the role of Supply chain risk resilience and performance. We believe that Supply chain risk resilience is the premise for firm performance, and Firm performance is also the foundation for better supply chain risk resilience. Therefore, we test the following two opposite models:

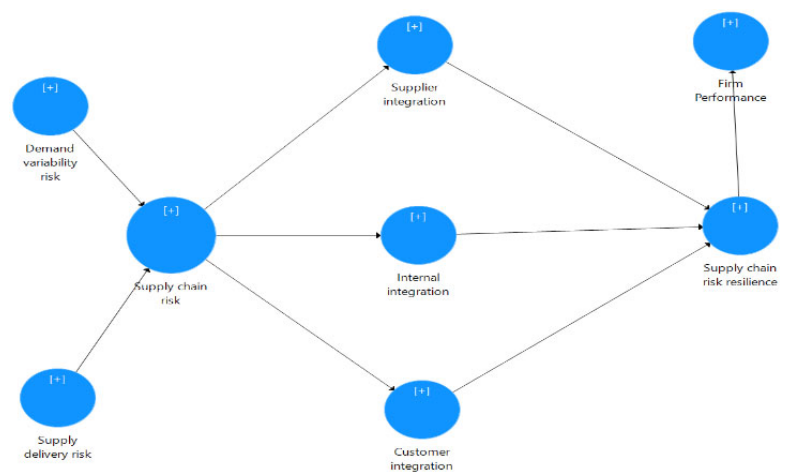

Fig. 8. Supply chain risk resilience is the intermediary for Supply chain Integration and Firm performance

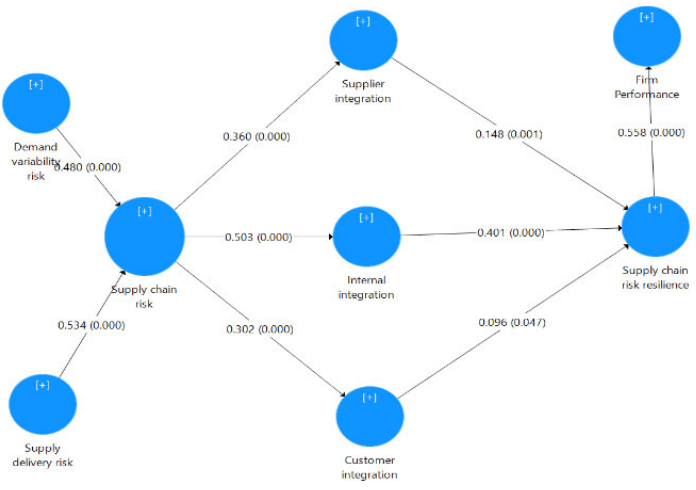

Fig. 9. The intermediary role of Supply chain risk resilience

The results in Fig. 9 show that all three aspects of supply chain Integration are Supplier Integration; Internal Integration and Customer Integration both have a statistically significant impact on Supply chain risk resilience and at this time Supply chain risk resilience has a very strong impact on firm performance with an impact factor of 0.558 at $1 \%$ significance level (P-value $=0.000)$. However, in the overall SEM model shown in Figure 3, Supply chain risk resilience still has a statistically significant impact on firm performance, so according to Hair et al. (2014) supply chain risk resilience does not act as an intermediary in the relationship between Supply chain integration and firm performance. The summary of the research hypotheses in this model is as follows:

Table 7

Path Coefficients (Mean, STDEV, T-Values, P-Values)

\begin{tabular}{|c|c|c|c|c|c|}
\hline & $\begin{array}{c}\text { Original } \\
\text { Sample }(\mathrm{O})\end{array}$ & $\begin{array}{c}\text { Sample } \\
\text { Mean (M) }\end{array}$ & $\begin{array}{c}\text { Standard Deviation } \\
\text { (STDEV) }\end{array}$ & $\begin{array}{c}\text { T Statistics } \\
(|\mathrm{O} / \mathrm{STDEV}|)\end{array}$ & $\begin{array}{c}\mathrm{P} \\
\text { Values }\end{array}$ \\
\hline Customer integration $\rightarrow$ Supply chain risk resilience & 0.096 & 0.097 & 0.048 & 1.988 & 0.047 \\
\hline Demand variability risk $\rightarrow$ Supply chain risk & 0.480 & 0.480 & 0.007 & 67.075 & 0.000 \\
\hline Internal integration $\rightarrow$ Supply chain risk resilience & 0.401 & 0.402 & 0.052 & 7.657 & 0.000 \\
\hline Supplier integration $\rightarrow$ Supply chain risk resilience & 0.148 & 0.146 & 0.045 & 3.257 & 0.001 \\
\hline Supply chain risk $\rightarrow$ Customer integration & 0.302 & 0.305 & 0.047 & 6.373 & 0.000 \\
\hline Supply chain risk $\rightarrow$ Internal integration & 0.503 & 0.504 & 0.040 & 12.438 & 0.000 \\
\hline Supply chain risk $\rightarrow$ Supplier integration & 0.360 & 0.360 & 0.048 & 7.506 & 0.000 \\
\hline Supply chain risk resilience $\rightarrow$ Firm Performance & 0.558 & 0.558 & 0.044 & 12.778 & 0.000 \\
\hline Supply delivery risk $\rightarrow$ Supply chain risk & 0.534 & 0.534 & 0.008 & 69.702 & 0.000 \\
\hline
\end{tabular}

Finally, we examine the supporting role of firm performance in Supply chain risk resilience as follows:

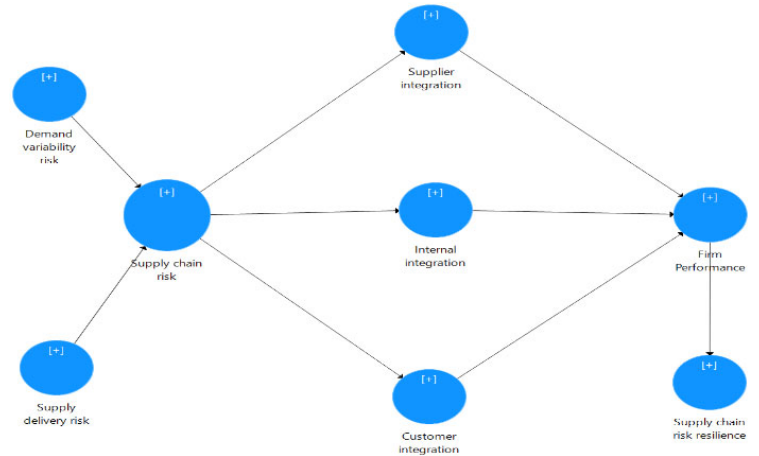

Fig. 10. Role of Firm performance

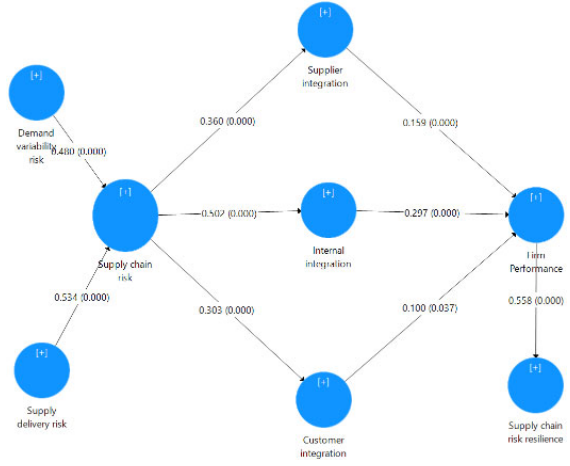

Fig. 11. Results of testing the role of Firm performance 
The results show that when considering the synthesis of Firm performance, the aspects in Supply chain Integration have a statistically significant positive impact on Firm performance when not considering Supply chain risk resilience. This means, when considering the role of Supply chain risk resilience in the relationship between Supply chain Integration and Firm performance, Supply chain Integration does not have a statistically significant relationship with firm performance. Because Firm performance is the premise for supply chain risk resilience activities. If the enterprise has good performance, the risks and disruptions in the supply chain occur, for example, the Covid-19 pandemic, the enterprise still has better supply chain risk resilience. The results summarize the impact and statistical significance as follows:

Table 8

Path Coefficients (Mean, STDEV, T-Values, P-Values)

\begin{tabular}{|c|c|c|c|c|c|}
\hline & Original & Sample & Standard Deviation & T Statistics & P Values \\
\hline Customer integration $\rightarrow$ Firm Performance & 0.100 & 0.100 & 0.048 & 2.086 & 0.037 \\
\hline Demand variability risk $\rightarrow$ Supply chain risk & 0.480 & 0.480 & 0.007 & 66.977 & 0.000 \\
\hline Firm Performance $\rightarrow$ Supply chain risk resilience & 0.558 & 0.558 & 0.044 & 12.782 & 0.000 \\
\hline Internal integration $\rightarrow$ Firm Performance & 0.297 & 0.299 & 0.052 & 5.770 & 0.000 \\
\hline Supplier integration $\rightarrow$ Firm Performance & 0.159 & 0.159 & 0.044 & 3.643 & 0.000 \\
\hline Supply chain risk $\rightarrow$ Customer integration & 0.303 & 0.304 & 0.047 & 6.488 & 0.000 \\
\hline Supply chain risk $\rightarrow$ Internal integration & 0.502 & 0.503 & 0.040 & 12.620 & 0.000 \\
\hline Supply chain risk $\rightarrow$ Supplier integration & 0.360 & 0.360 & 0.047 & 7.601 & 0.000 \\
\hline Supply delivery risk $\rightarrow$ Supply chain risk & 0.534 & 0.534 & 0.008 & 69.844 & 0.000 \\
\hline
\end{tabular}

\section{Discussion}

When participating in global supply chains, which means accessing a larger risk environment, it is necessary to equip yourself with the basic capabilities of visibility, flexibility, collaboration capacity, control ability. Therefore, businesses should prepare well response strategies, such as:

Buffer storage strategy: The classic and simplest strategy for creating resilience. The difficulty is that supply chain managers often find it difficult to demonstrate that they are appropriate under normal conditions. Network diversification strategy: Focus on diversifying supply sources or production facilities. Allow the company to switch to new suppliers or ask existing partners to supply from new sources. At this point, the cost of maintaining multiple supply locations must be emphasized rather than the cost of doing business.

Multidisciplinary Strategy: Supply chain leaders need to know the details of their supplier networks and categorize suppliers not just by volume, but by the impact on revenue when an outage occurs. Encourage additional suppliers or connect with suppliers that can produce in multiple locations.

Localization Strategy: Helps reduce geographic dependence in the global network and shortens cycle times for finished products. Regional or local supply chains can be more expensive due to more attendees and increased complexity. But better inventory control and bring products closer to the end consumer.

Product or factory platform harmonization strategy: When the supply network is localized, the more the factories' technology is harmonized, the more seamless and smooth the product movement will be. The production platform common to many different models in the automotive industry is a prime example of this harmony. Standardizing the details of a product category is another form of harmonization that allows for great interchangeability. This simplifies sourcing policies and creates the opportunity to place higher volumes between multiple suppliers, thereby enhancing resiliency.

Partnership development strategy: In addition to sourcing diversity, cooperation with strategic material suppliers and external service partners is important to ensure better preparedness for resistance. withstand and recover. Building strong relationships with contract manufacturers and global 3PLs is important for multinational markets.

Strategies to optimize production and distribution capacity: Disruptions often reduce the need to sell, and this strategy helps to conserve resources and maintain the survival of the company. There should be clear communication with employees about the risks of working and remote and homework options.

Strategies to maintain logistics capacity: As the glue that holds the supply chain together, logistics capacity in times of crisis has a top priority. Therefore, it is necessary to plan logistics capacity at a long-term strategic level to help proactively always exploit at reduced costs. The long-term cooperation strategy with logistics partners is also very effective to get priority and increase capacity on favorable terms.

Financial strategy: When the crisis unfolds, it will put pressure on earnings and liquidity, this time it is necessary to manage cash and working capital. It is possible to reduce finished goods inventories, improve logistics such as smarter fleet 
management to delay capital costs significantly without impacting customer service. Pressure test suppliers' orders, reduce or eliminate purchasing of unnecessary supplies to reduce cash out immediately.

Building resilience: Once the immediate risks to the supply chain are under control, leaders must focus on designing a sustainable supply chain for the future. First, set up a supply chain risk function that can assess risks, continuously update impact estimates, monitor, warn, and remediate risks. This is the department that continuously monitors supply chain vulnerabilities. Processes and tools created during the crisis management phase should be codified into a formal document as the basis for lasting solutions. Investing in modern technologies such as digitization and automation are expensive but necessary measures to help businesses increase their strength to cope with risks when supply chains are disrupted, leading to collapse and disruption of the entire supply chain. Digitizing supply chain management improves speed and accuracy. Modern technology like robotics, artificial intelligence (AI) and 3D printing help move manufacturing closer to the point of sale. Thanks to these technologies, the supply chain will shorten the time to rebuild or move by shrinking in the region rather than expanding globally. This is a long-term investment strategy that minimizes the risk of a company or country being cut off from its supply chain. Supply chain restructuring towards sustainability or supply chain integration will promote the development of a circular economy. Supply chains structured in the direction of lean, safe, and environmentally friendly will ensure to avoid possible risks in the future. The circular economy model can help increase the efficiency of local supply chains, by using readily available materials as inputs for production. Enterprises can develop plans to recycle and reuse wastes after production and business processes, especially plastic waste, to replace the interrupted capital supply.

\section{Conclusion}

Risk management is not just about immediate and situational measures. When participating in global supply chains, having ready capabilities and risk response plans should be considered as a mandatory requirement for Vietnamese pharmaceutical enterprises. Moreover, when reaching out to global markets, developing sustainable supply chains is a radical and long-term solution for businesses. Risks in the supply chain are inevitable and completely disappear, so businesses need to take measures to limit them:

- For internal risks: Enterprises need to list the risks according to the possibility of happening to their businesses, from which to plan to limit and control.

- For external risks: Enterprises need to select qualified parties to best limit risks.

To minimize the negative impacts caused by risks, Vietnamese pharmaceutical enterprises need to prepare a supply chain risk management report according to the risk management process as follows:

\subsection{Identify and profile risks}

First, Vietnamese pharmaceutical enterprises need to identify possible supply chain risks at each node of the supply chain suppliers, factories, warehouses, and shipping routes. Risks are entered into a risk register and closely monitored on an ongoing basis. At the same time, building a risk-aware culture helps businesses react faster when risks appear. A culture of risk perception helps businesses establish and maintain strong defenses against unknown risks. Also react faster when an unknown risk appears and threatens the operation of the business.

- Recognition: Management and employees need to be empowered to know about company failures and learn from previous mistakes. This openness fosters an environment where you can speak up and solve problems. Culturally, it is important that businesses do not get discouraged or focus solely on holding accountable when a risk occurs, but instead work together towards a quick solution.

- Transparency: Leaders must clearly and transparently define the risk tolerance of the business. Mitigating risk often has an increased cost involved. And so it is important to base on which risks need to be mitigated and which risks the business can bear. The corporate culture must also allow for the public sharing of warning signs of internal and external risks.

- Responsiveness: Employees need to be empowered to perceive and react quickly to external change. This can be encouraged by creating an ownership environment where members feel the need to take responsibility for the results of their actions and decisions.

- Respect: The employee's concern for risk must be consistent with the business, to avoid individuals or groups not taking risks or acting only to benefit themselves but harm the business.

\subsection{Building a supply chain risk management framework}

To build an integrated risk management framework, every risk in the registry must be scored on three aspects: 
- Impact on the organization if a risk occurs.

- Possibility of risk.

- The organization's preparedness to deal with that particular risk.

It is important to design and use a consistent scoring method to assess all risks. This allows prioritization of the threat level of the risks and the probability of loss of those risks.

\subsection{Risk monitoring}

Always monitor and monitor to identify risks that can cause damage to the business: Once a risk management framework is established, continuous monitoring is one of the key success factors in identifying risks. Identify risks that may cause damage to the business. The recent emergence of digital tools has made this possible for even the most complex supply chains, by identifying and tracking leading risk metrics. Effective monitoring systems will be customized to business needs, incorporating impact, likelihood and preparedness predictions.

\subsection{Regular risk management and assessment}

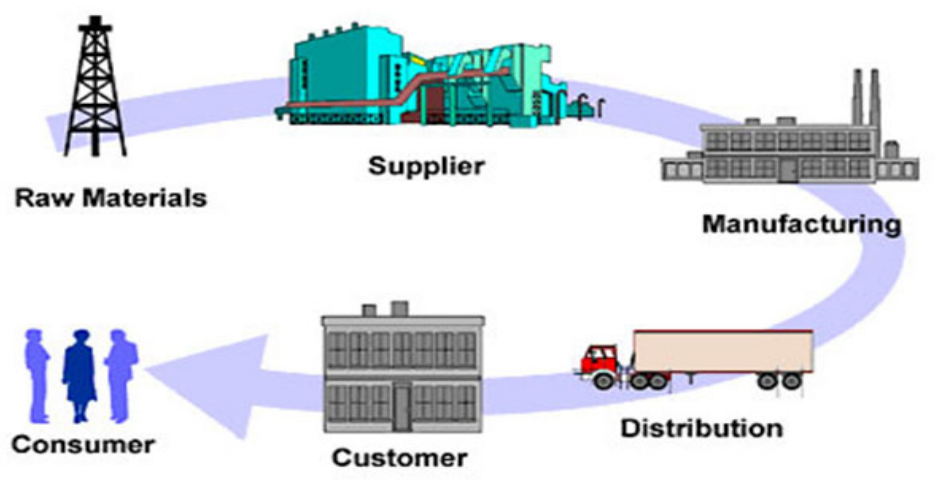

Fig. 12. The Board of Directors consists of representatives of the parties involved in the supply chain

An important final step is to establish a governance mechanism to periodically monitor risks in the supply chain and identify measures to mitigate and improve supply chain resilience and flexibility. The management board consists of representatives of the parties involved in the supply chain. Management will meet periodically to review the leading risks in the supply chain and identify mitigation methods.

\subsection{Digital transformation of the supply chain of Vietnamese pharmaceutical enterprises}

Over the past 30 years, the supply chain has undergone a tremendous change. The focus of the supply chain management function has shifted to advanced planning processes, such as analytical demand planning or integrated sales and operations (S\&OP) planning), which has become an established business process in many companies, while logistics is often outsourced by 3PLs (third-party logistics providers). The supply chain function ensures that operations are well integrated, from supplier to customer, with cost, inventory and customer service decisions made from an end-to-end point of view, not an end-to-end point of view. must follow each function individually. Digitization creates disruption and requires companies to rethink the way their supply chains are designed. At the same time, customer expectations are growing and the recent online trends have led to increasing service expectations combined with highly detailed orders. In addition, a certain trend towards further personalization and customization is driving strong growth and constant changes in product portfolios (SKUs). Transparency supported by online and easy access to a multitude of options regarding where and what to buy drive the competition of supply chains. Supply chain digitization allows companies to address new customer requirements, supply-side challenges, and residual expectations in terms of efficiency improvement.

\section{Acknowledgement}

This research is funded by National Economics University, Hanoi, Vietnam.

\section{References}

Chin, W.W. (2010). How to Write Up and Report PLS Analyses. In: Esposito Vinzi, V., Chin, W.W., Henseler, J. and Wang, H., Eds., Handbook of Partial Least Squares: Concepts, Methods and Applications, Springer, Heidelberg, Dordrecht, London, New York, 655-690. https://doi.org/10.1007/978-3-540-32827-8 29 
Chopra, S., \& Sodhi, M.S. (2014). Reducing the risk of supply chain disruptions. MIT Sloan Management Review, 55(3), 7380.

Dubey, R., Gunasekaran, A., Childe, S.J., Papadopoulos, T., Blome, C., \& Luo, Z. (2019). Antecedents of resilient supply chains: an empirical study. IEEE Transactions on Engineering Management, 66(1), 8-19.

Hair, J.F., Ringle, C.M., \& Sarstedt, M. (2011). PLS-SEM: indeed a silver bullet. Journal of Marketing Theory and Practice, 19(2), 139-151.

Hair, J.F., Hult, G.T.M., Ringle, C., \& Sarstedt, M. (2013). A Primer on Partial Least Squares Structural Equation Modeling (PLS-SEM), Sage Publications Ltd, London.

Hair, J.F., Henseler, J., Dijkstra, T., Sarstedt, M., Ringle, C., Diamantopoulos, A., Straub, D., Ketchen, D., GTM, H., \& Calantone, R. (2014). Common beliefs and reality about partial least squares: comments on Rönkkö and Evermann. Organizational Research Methods, 17(2), 182-209.

Hair, J. F., Hult, G. T. M., Ringle, C. M., \& Sarstedt, M. (2017). A Primer on Partial Least Squares Structural Equation Modeling (PLS-SEM), $2^{\text {nd }}$ ed., Sage: Thousand Oaks.

Henseler, J., Ringle, C.M., \& Sarstedt, M. (2015). A new criterion for assessing discriminant validity in variance-based structural equation modeling. Journal of the Academy of Marketing Science, 43(1), 115-135.

Henseler, J., Ringle, C.M., \& Sinkovics, R.R. (2009). The use of partial least squares path modeling in international marketing. in Sinkovics, R.R. and Ghauri, P.N. (Eds), New Challenges to International Marketing, Emerald Group Publishing Limited.

Linnenluecke, M.K. (2017). Resilience in business and management research: a review of influential publications and a research agenda. International Journal of Management Reviews, 19(1), 4-30.

Lu, Q., Chen, J., Song, H., \& Zhou, X. (2021), Effects of cloud computing assimilation on supply chain financing risks of SMEs, Journal of Enterprise Information Management, Vol. ahead-of-print No. ahead-of-print. https://doi.org/10.1108/JEIM-11-2020-0461

Marucheck, A., Greis, N., Mena, C., \& Cai, L. (2011), Product safety and security in the global supply chain: Issues, challenges and research opportunities. Journal of Operations Management, 29(7-8), 707-720.

Nitya, P. S., \& Singh, S. (2019). Building supply chain risk resilience: Role of big data analytics in supply chain disruption mitigation. Benchmarking, 26(7), 2318-2342. doi:http://dx.doi.org/10.1108/BIJ-10-2018-0346

Nguyen, T., Pham, T., Phan, T., Than, T \& Nguyen, T. (2020). Impact of green supply chain practices on financial and nonfinancial performance of Vietnam's tourism enterprises. Uncertain Supply Chain Management, 8(3), 481-494.

Phan T. T. H, Doan X. T., \& Nguyen T. T. T. (2019). The impact of supply chain practices on performance through supply chain integration in textile and garment industry of Vietnam. Uncertain Supply Chain Management, 8(1), $175-186$.

Phan, T. T. H., Tran, H. X., Le, T. T., Nguyen, N., Pervan, S., \& Tran, M. D. (2020). The Relationship between Sustainable Development Practices and Financial Performance: A Case Study of Textile Firms in Vietnam. Sustainability, 12(15), 5930.. https://doi.org/10.3390/su12155930.

Pham, T \& Phan, T. (2020). How to improve financial performance of tourism and travel enterprises: The case of Vietnam. Accounting, 6(3), 335-344.

Punniyamoorthy, M., Thamaraiselvan, N., \& Manikandan, L. (2013). Assessment of supply chain risk: scale development and validation. Benchmarking, 20(1), 79-105.

Revilla, E., \& Saenz, M.J. (2017). The impact of risk management on the frequency of supply chain disruptions: a configurational approach. International Journal of Operations \& Production Management, 37(5), 557-576.

Sharma, S., Routroy, S., Irani, Z., \& Irani, Z. (2016). Modeling information risk in supply chain using Bayesian networks. Journal of Enterprise Information Management, 29(2), 238-254.

Shen, B. \& Li, Q. (2017). Market disruptions in supply chains: a review of operational models. International Transactions in Operational Research, 24(4), 697-711.

Tran, M., Phan, T., Ha, H \& Hoang, T. (2020). The impact of transactional leadership on supply chain quality and performance. Uncertain Supply Chain Management, 8(4), 773-784.

Tran, M., Phan, T., Ha, H \& Hoang, T. (2020). The impact of supply chain quality integration on green supply chain management and environmental performance in Vietnam's tourism industries. Uncertain Supply Chain Management, 8(4), 693-704.

Yu, Y., Xiong, W., \& Cao, Y. (2015). A conceptual model of supply chain risk mitigation: The role of supply chain integration and organizational risk propensity. Journal of Coastal Research, 5(73), 95-98.

Zhao, L., Huo, B., Sun, L., \& Zhao, X. (2013). The impact of supply chain risk on supply chain integration and company performance: A global investigation. Supply Chain Management, 18(2), 115-131. doi:http://dx.doi.org/10.1108/13598541311318773

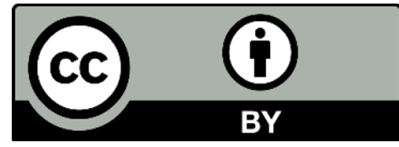

(C) 2021 by the authors; licensee Growing Science, Canada. This is an open access article distributed under the terms and conditions of the Creative Commons Attribution (CCBY) license (http://creativecommons.org/licenses/by/4.0/). 